\section{Blanca Cárdenas Fernández}

Doctora en Estudios Hispánicos y Latinoamericanos por la Universidad de Perpignan, Francia. Es profesora-investigadora de tiempo completo en la Escuela de Lengua y Literaturas Hispánicas de la Universidad Michoacana de San Nicolás de Hidalgo de Morelia, Michoacán. Autora de los libros Los cuentos en lengua p'urhépecha. Un punto de de vista sociocrítico e In Auencias e ideología en la obra de Rubén Romero, 'Apocalipsis'. Es además editora y coautora de una docena de libros y autora de varios artículos en publicaciones nacionales e internacionales. Miembro fundador del Seminario interuniversitario de Estudios Sociocríticos y Semióticos. Pertenece al Sistema Nacional de Investigadores de México con nivel II.

\title{
CH'ANANTSKUA (JUEGO DE LA MADUREZ)
}

\author{
BLANCA CÁRDENAS FERNÁNDEZ
}

\section{RESUMEN}

La Ch'anantskua (juego de la madurez), propia del pueblo de Carapan, Michoacán, es una representación ancestral de iniciación de los jóvenes al matrimonio. Esta representación consiste en la demostración que hacen los muchachos (actores), de ambos sexos, ante la población adulta (jueces y público a la vez) de que ya son aptos para el matrimonio; para ello realizan públicamente labores propias de su sexo. Sin embargo, a partir de los años sesenta, esta representación fue incorporando elementos religiosos cristianos, así como profanos referentes al carnaval, de tal suerte que hoy se ha transformado en una amalgama de signos, símbolos e iconos de las culturas p'urhépecha prehispánica, negra y española, que se expresan en una rica polisemia cultural, que pretendemos mostrar en este artículo.

\section{CH'ANANTSKUA (THE GAME OF MATURITY)}

\begin{abstract}
Ch'anantskua (the game of maturity), from the village of Carapan in Michoacan is an ancestral representation of young people's journey into marriage. This representation demonstrates to the adult population (judges and public alike) that the youths (actors) from both sexes are ready for marriage. So as to do this, they publicly carry out work considered inherent to their gender. However, from the sixties, this representation began to include Christian religious elements as well as secular referents from carnivals. In this way, it has today been transformed into an amalgam of signs, symbols and icons of the pre-Hispanic p'urbépecha, black and Spanish cultures, expressed via a rich cultural polysemy that this article aims to demonstrate.
\end{abstract}

\section{Agradecimientos a Saira Arias Pablo por el material proporcionado}

Ch'anantskua o «juego de la madurez» es una fiesta de la comunidad p'urhépecha de Carapan, ubicada en la Cañada de los Once Pueblos. Se trata de una representación que hacen los jóvenes del rol socio-económico de los adultos: «juegan» a ser «grandes» realizando el trabajo propio de las personas maduras; así, muchachos y muchachas demuestran ante el pueblo que ya son aptos para el matrimonio. Ellos realizan labores del campo (principalmente cortar leña) pero también hacen patente su «hombría» tomando bebidas embriagantes y jugando a pelear entre ellos. Ellas, por su parte, evidencian su saber en 
bordar un mantel o servilleta y en preparar los alimentos: chapatas ${ }^{1}$, curundas ${ }^{2}$ y churipo ${ }^{3}$. «Si las muchachas ya saben hacer chapatas ya pueden casarse, ya están preparadas para el matrimonio» 4 .

En la representación teatral de este «juego» existe una interacción entre el actor y el público, entre el joven y el adulto; cuando el primero tiene alguna dificultad para realizar un trabajo, éste interviene para enseñarle la manera de hacerlo, lo que le da a la representación un carácter de «rito de iniciación» del joven a la vida adulta. «En el juego piden ayuda a los adultos cuando algo se les complica» ${ }^{5}$.

La celebración dura cuatro días, y el escenario donde se desarrolla es el área geográfica del pueblo, el cual se encuentra dividido, para cualquier tipo de actividad, en cuatro partes llamadas cuarteles. «Los jóvenes de los cuatro cuarteles hacen los preparativos dos o tres meses antes, poniéndose de acuerdo con su novia o amiga (...) para que prepare una servilleta, que luego (él) lucirá en la fiesta» ${ }^{6}$. Además, como ellos mismos son los "comisionados", adquieren el compromiso de organizarse para repartirse actividades como la contratación de bandas de música, velar por el buen desarrollo de la fiesta, buscar el árbol del cual se harán los trozos de leña, hacer banderitas de papel de china de diferentes colores que repartirán a sus novias y a los espectadores. Estas banderitas tienen en su centro dibujadas (o caladas) las figuras de un hombre y una mujer como significado de este juego. Sin embargo, la bandera más importante que los jóvenes portan en la fiesta es la servilleta bordada por su novia. Este mantel o servilleta lo amarran con listones de muchos colores a un carrizo, el cual sirve de asta. En los últimos cuarenta años esta servilleta tiene bordadas, en punto de cruz, las figuras de una mujer vestida de china poblana, un torero y un toro.

El ritual de la fiesta, según Carlos Marcelo Valentín 7 , comienza con la entrada al pueblo de las bandas de música; delante de ellas van los jóvenes recorriendo los cuatro cuarteles del pueblo. Un día después se organiza una comida tradicional para actores y espectadores, en ella se ofrece churipo y curundas, y se les obsequia una chapata a cada uno de los asistentes.

El tercer día los jóvenes visitan las casas de los cuatro cuarteles. Cuando sale una muchacha con su servilleta y se la da al joven correspondiente, éste baila hasta dos abajeños, ella por su parte le regala una chapata $y$, reciente-

mente, también una botella de vino para que la comparta con los demás jóvenes. En el transcurso del recorrido que se hace por los cuatro barrios se van sumando a él las múchachas que han dado la servilleta, los adultos y espectadores visitantes; todos siguen el camino rumbo al árbol que ha sido derribado y cortado en trozos. Al llegar a él, los jóvenes co-

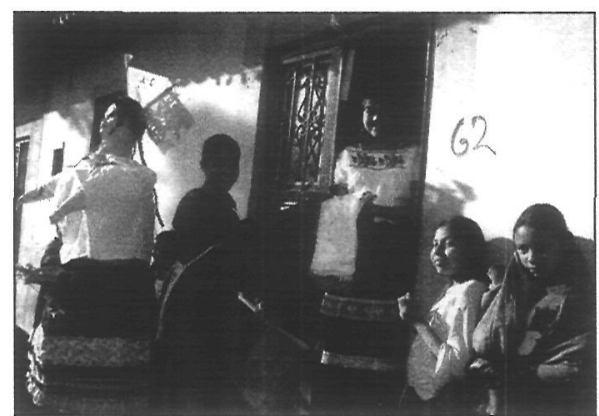

Fiesta de la madurez. Muchacha que ha bordado sus manteles. mienzan a bailar y a repartir brazadas de leña y banderitas de colores a las chicas para que ellas lleven luego la leña al atrio del templo. El cuarto día se hace una procesión con el Señor del Rescate acompañado de otras imágenes religiosas como la Virgen María y San Isidro Labrador. Al finalizar, los jóvenes y demás espectadores despiden a las cuatro bandas de música y las muchachas le regalan una chapata a cada uno de los músicos.

Ch'anantskua se encuentra estrechamente vinculada a la organización de las fiestas prehispánicas, principalmente a tres de ellas: a la de Sicuindiro, que es una representación cósmica del número cuatro en la que se venera a los dioses de las cuatro partes del mundo, a otras festividades ligadas a los rituales de la fertilidad y a la correspondiente a las bodas.

En la Relación de Michoacán se describen varias celebraciones que ponen en evidencia el número cuatro; otras de ellas se refieren al rol de la producción agrícola, que va desde la petición de las lluvias a las cosechas, como ya habíamos comentado. La fiesta religiosa de Sicuindiro es una de ellas y estaba dedicada a los dioses de las cuatro partes del mundo para obtener lluvias abundantes que redundaran en buenas cosechas.

... éstos (los señores principales) representaban las nubes blanca y amarilla, colorada y negra, disfrazándose para representar cada nube de éstas. Habiendo de representar la nube negra, vestíanse de negro y así las otras. Y bailaban estos allí con los otros y otros cuatro sacerdotes que representaban otros dioses que estaban con la dicha Cuerauaperi'.

El escenario de la fiesta simboliza las cuatro partes del universo, cada una de las cuales está representada por un dios, y una nube de color de acuerdo al punto cardinal del que se trate. En esta cultura el cuadrado derivado de la divinidad de la constelación de la Cruz del Sur es una alegoría del espacio cósmico celeste; sin embargo, este modelo es reproducido
1 Tamales grandes rellenos de frijoles molidos con piloncillo.

2

Otro tipo de tamal que puede estar relleno de carne con chile.

3

Carne de res cocida con col y guisada con chile rojo, se come con las curundas.

4 Comentarista del vídeo Ch'anantskua. El juego de la madurez, realización y guión de Dante Cerano Bautista, Videoteca Iberoamericana I, México, 1999.

5

Ibidem.

6

J. Guadalupe Aguilar Ortiz, Carapan: ir escribiendo, Zamora, editora del Semanario Guía, 1997, pág. 18.

7

Locutor de Radio Cheran y de la ZM de Zamora, en J. Gudalupe Ortiz, op.cit., págs. 18-20.

8

Jerónimo de Alcalá, Relación de Michoacán, México, SEP, 1988, pág. 49. 


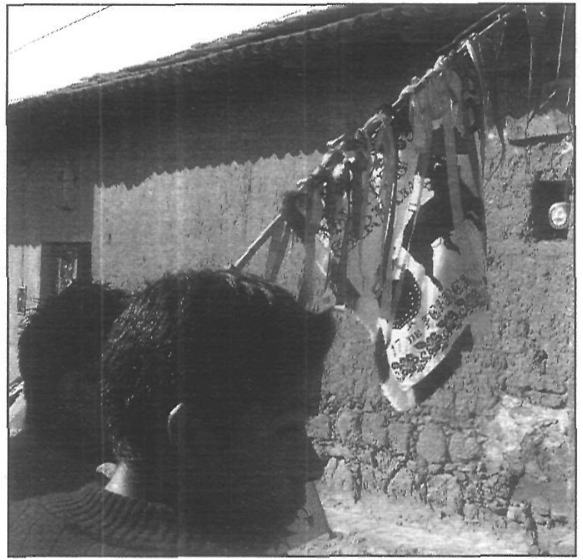

Joven portando el mantel de su novia en la fiesta. también en la tierra y en el inframundo. Tal figura dominante en los tres lugares cósmicos se hace presente aún hoy en día en los rituales religiosos y en la vida social de este pueblo.

En Ch'anantskua queremos señalar algunos aspectos de la subsistencia de la representación del cuadrado: el escenario se divide en cuatro partes, la fiesta tiene una duración de cuatro días (de lunes a jueves), se contratan cuatro bandas de música, los jóvenes se organizan en cuatro grupos, entre otros. Aquí se muestra cómo aún subsiste la visión del cosmos sagrado en las fiestas actuales, puesto que el número cuatro se reproduce a nivel cultural no sólo en el espacio geográfico y en aspectos divinos como templos, deidades y rituales, sino también a nivel social en costumbres y leyes que rigen al pueblo p'urhépecha.

Los ritos de fertilidad los encontramos en la coincidencia en fechas de la representación de la fiesta actual con las de las celebraciones antiguas; por ejemplo en la de Euanscunícuaro, de enáscuni (sembrar):

...era el mes de la siembra, del 9 al 28 de abril. Desfile de doncellas con sus canacuas (coronas de flores) y mancebos con sus tarecuas, (coas para la siembra). Era de cantos, de alegría, de tierra abierta, de bebidas frescas (...) de chapata, pan de bledos, de chía o de amaranto. Todo lo regía la mano de los dioses, pero también el ciclo del maíz, vida y carne del hombre»?

Sin embargo, Ch'anantskua parece haber tomado también algunos elementos, principalmente, de la fiesta celebrada en el mes de charapuzapi ("Charapu, rojo, bermejo. Y sapi, niño adolescente o joven» ${ }^{10}$ ). Era la fiesta de los niños, de los jóvenes, que se celebraba del 16 de septiembre al 5 de octubre. Esto coincide con lo que comenta Mircea Eliade de que la sexualidad en los ritos agrarios es propia de varias culturas, en muchas de las cuales se dan bodas o uniones de jóvenes en los surcos ${ }^{11}$.

En lo que respecta a las bodas antiguas, los elementos de la fiesta actual que se encuentran íntimamente relacionados con el ritual del matrimonio prehispánico son: los cuatro días, la leña, la servilleta y las chapatas, principalmente. En las bodas de los p'urhépecha prehispánicos había intercambio de ajuares:
[Ella] llevaba mantas para su esposo y camisetas y hachas para la leña de los cues, con las esteras que se ponían a las espaldas, y estaba él aparejado y tenía allí su pan de bodas, que eran unos tamales muy grandes llenos de frijoles molidos y jicales y mantas y cántaros y ollas y maíz y ají y semillas de bledos y frijoles en sus trojes; y tenía allí un rimero enaguas y atavíos de mujeres ${ }^{12}$.

La novia (esposa) provee al esposo de camisetas y de las herramientas de trabajo para cortar leña; sin embargo, la leña que él corta no está destinada al hogar, sino a los dioses. También él proporciona a la esposa ropa y utensilios de cocina, pero también la comida suficiente que almacena en sus trojes.

Estos aspectos de la boda prehispánica se encuentran claramente presentes en la fiesta de Ch'anantskua o juego de la madurez, que bien puede identificarse con un ritual de iniciación al matrimonio; por esto se le llama fiesta de los jóvenes o fiesta de las chapatas. Las chapatas o "pan de boda», como se le llama en la Relación de Michoacán, tienen un papel relevante tanto en el ritual antiguo como en el presente, ya que caracteriza a ambos. Cuando Jerónimo de Alcalá menciona el «pan de boda», lo hace para referirse al momento en que llega la novia a la casa del novio para recibir los consejos del sacerdote y efectuar la fiesta: «...y así llegaban a la casa del esposo, donde ya estaba él aparejado y tenía allí su pan de boda, que eran unos tamales muy grandes llenos de frijoles molidos ${ }^{13}$. En la fiesta actual se dice que las chapatas son tamales grandes «hechos de harina, frijol molido, endulzado con piloncillo, envueltas con hojas de matas de maíz (...); se preparan desde tres días antes y se reparten primero entre los cuñados y abuelos» ${ }^{14}$. Repartir las chapatas primero entre los cuñados y abuelos es un hecho que remite también a las bodas prehispánicas, en las que se priorizan los parientes políticos de los novios y a los ancianos.

La leña es otro elemento de relevancia también en ambos tiempos: en el antiguo el novio la lleva a los cues o altares de los dioses en abstinencia sexual; en las bodas prehispánicas, antes de tener relaciones sexuales, el novio

...iba cuatro días por leña (...) para los cues y la mujer barría su casa y un gran trecho del camino por donde entraban a su casa. Y esto era oración que hacían por ser buenos casados y por durar en su casamiento muchos días en significación de lo cual barría el camino (...) y después se juntaban en uno ${ }^{15}$. 
En este ritual prehispánico aparece el simbolismo sagrado del cuatro: ir por leña cuatro días, barrer la casa y el camino cuatro días en abstinencia sexual para agradar a los dioses y poder ofrecer a éstos su matrimonio. En el Michoacán antiguo la leña es una ofrenda propia de los dioses, como puede comprobarse a lo largo de la Relación de Michoacán, donde encontramos personajes importantes cortando leña para hacer fuego en los cues en honor a sus deidades. En la fiesta actual los jóvenes deben demostrar ante el pueblo que ya saben cortar leña y tumban un árbol para hacer pilas pequeñas de ésta, las cuales reparten entre las muchachas; ellas la cargan y se van bailando hasta el atrio de templo, donde la obsequian al sacerdote. Antes, dice Raymundo Madrigal Baltasar oriundo de Carapan,

...la leña era depositada en la iglesia, por eso se juntaba muchísima entre los cuatro cuarteles. Esta leña era utilizada por el sacerdote durante todo el año (...), la leña tenía un simbolismo muy especial como símbolo de la fuerza de los jóvenes, como muestra de cumplimiento ${ }^{16}$.

En la observación que hace don Raymundo Madrigal encontramos la conjugación de los tiempos pasado y presente, de lo pagano y lo sagrado, en tanto en la actualidad lo sagrado p'urhépecha o pagano ha tomado un simbolismo cristiano: la leña propia de los dioses prehispánicos es ahora traspasada al sacerdote católico, pero como ritual sagrado antiguo toma un cariz profano cuando se transforma en símbolo de la potencia juvenil.

Las servilleta, o pedazo de tela bordado que se utiliza para envolver las tortillas de maíz, es algo indispensable para la mujer indígena, es un objeto de cocina que no debe faltar en el hogar, por esto puede ser asociada con los objetos de cocina que, en el ritual prehispánico, regala el novio a la novia: «jicales y mantas y cántaros y ollas».

Esta fiesta de los jóvenes, tan relacionada con el ritual del matrimonio prehispánico, ha ido cambiando con el tiempo; incluso los objetos anteriores, que aún subsisten, han sufrido transformaciones debidas a la incorporación de elementos de otras culturas que celebran festividades por la misma fecha que Ch'anantskua, como son la Semana Santa y el Carnaval, de tal suerte que el ritual religioso prehispánico toma matices paganos del Carnaval, pero al mismo tiempo se cristianiza con el recuerdo de la crucifixión de Cristo. De esta forma, Ch'anantskua es hoy en día una fiesta híbrida rica en simbolismos e iconos de diferentes culturas.

Los elementos que en los últimos años ha incorporado Ch'anantskua o «juego de la madurez», son los relacionados con el cristianismo y con la cultura africana; de esta última encontramos principalmente aquellos derivados del Carnaval, específicamente de la celebración del «Torito de petate». Como explica Jorge Amós, el toro de petate es «una tradición de origen africano traída (...) en el siglo XVII»17; las danzas de esta fiesta imitan al 'toro', $y$ «se encuentran generalmente entre los grupos bantú del sur de África» ${ }^{18}$. Creemos que esta adopción por los p'urhépecha se debe a la coincidencia de las fechas de celebración del torito y de Ch'anantskua, independientemente de que ambas tengan un propósito ritual de fertilidad, puesto que «es un 'toro negro' el que se sacrifica entre los bantú de África del Sur para pedir lluvia» ${ }^{19}$.

Respecto a la influencia católica, la gente de Carapan afirma que la fiesta comienza a cristianizarse cuando el padre Ernesto Buitrón llega al pueblo como párroco. Él incorpora a esta tradición la celebración del Señor del Rescate, que «es un santo muy milagroso, por lo que las personas del pueblo y sus alrededores colocan sobre su imagen diferentes tipos de ofrenda como dinero, entre otras cosas» ${ }^{20}$. El párroco del lugar, José Guadalupe Aguilar Ortiz, explica que «la imagen del señor del rescate se incrementó para que hubiera también un motivo religioso y no fuera únicamente el día de Ch'anantskua o fiesta. Fue como en el año de 1958 con el padre Buitron, con el fin de que no fuera únicamente la fiesta profana o comercial, sino que aparte hubiera también un motivo religioso, la imagen se venera en Tzintzuntzant» se «importa» de este pueblo ${ }^{21}$, pero con esta imagen se incorpora también la Virgen María porque ella «siempre acompaña a todos los santos en las procesiones», como afirma doña Elvira Erape.

Al mismo tiempo que se añaden los elementos cristianos, se da la importación de elementos carnavelescos, de tal forma que el recorrido que en un principio hacían los muchachos por los cuatro cuarteles del pueblo ahora se ha convertido en una procesión que semeja más a un desfile de Carnaval que a un evento religioso; en este desfile-procesión se
16

Don Raymundo Madrigal Baltasar, oriundo de Carapan.

17

Jorge Amós Martínez, Los «toros de petate». Una tradición de origen africano traída por los esclavos negros en el siglo XVII, tesis, Facultad de Historia, UMS$\mathrm{NH}, 1999$, pág. VI.

18

Ibidem, pág. 132.

19

Ibidem, pág. 131.

20

Doña Elvira Erape Baltasar, 68 años, oriunda de Carapan.

21

Don José Guadalupe Aguilar Ortiz, párroco de Carapan.

Ch'anantskua

(Juego de la madurez)

BLANCA CÁRDENAS FERNÁNDEZ 


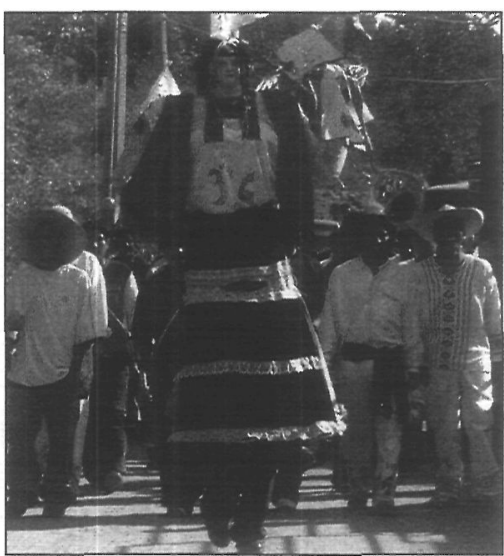

Mojiganga en la procesión de Ch'anantskua. exhiben tanto imágenes religiosas cristianas como toritos y mojigangas, de tal forma que la concepción que se tiene hoy en día acerca de Ch'anantskua es, como dice doña Elvira, "la fiesta de las chapatas, o lo equivalente a un carnaval, es la fiesta de la juventud. En la iglesia, se venera la imagen del Señor del Recate, pintura original de los señores Isidro Alejo y Francisco Pablo de Carapan» ${ }^{22}$. Vale la pena señalar la separación que hace la señora de lo profano y lo sagrado en su discurso al delimitar, por un lado, las fiesta de las chapatas, de carnaval, de la juventud y, por otro, la celebración del templo cristiano como algo aparte y reciente; esto se expone en la denuncia de que la imagen del Cristo fue hecha por la misma gente del pueblo: Isidro Alejo y Francisco Pablo.

Podemos decir entonces que Ch'anantskua Doña Elvira Erape.

23 Mircea Eliade, Lo sagrado y lo profano, Barcelona, Paidós, 1999, págs. 137-138.

24

Ibidem, pág. 138.

25

José Carmelo López, op. cit., pág. 30.

26

Ibidem, pág. 31.
Cb'anantskua (Juego de la madurez)

BLANCA CÁRDENAS FERNÁNDEZ actual es una simbiosis de los rituales de iniciación, de la fertilidad y del matrimonio prehispánicos, pero también esta amalgama de símbolos mezcla directamente al cristianismo y de manera indirecta a la cultura bantú del sur de África.

Decimos que hay signos del ritual de iniciación en esta fiesta-representación porque se inicia a los jóvenes al matrimonio. La aptitud para realizar los trabajos que corresponden al adulto los induce a la sexualidad, pero también los incorpora en el campo laboral, los hace apto para asumir la responsabilidad de estar casados. La iniciación que según Mircea Eliade «equivale a la madurez espiritual $\aleph^{23} \mathrm{en}$ Cb'anantskua corresponde a la madurez social y biológica, a la destreza demostrada para unirse al trabajo y a la vida sexual instituida.

El ritual de iniciación también se deja ver en que «los jóvenes candidatos soportan parte de sus pruebas y se les instruye en las tradiciones secretas de la tribu ${ }^{24}$, lo que podemos observar tanto en la Relación de Michoacán como en Ch'anantskua, sólo que no en las tradiciones 'secretas', sino en los rituales de tradiciones públicas: lo cerrado del ritual se transforma en abierto, más en esta última, ya que agrega no sólo a los familiares de los novios sino a la comunidad entera. Sin embargo, en la fiesta de Carapan se da una desacralización del ritual prehispánico al convertirse sólo en un juego de la madurez, juego que, contrariamente al concepto que representa, posee tal connotación de seriedad, que al final de él surgen varias parejas de casados.
El espacio del ritual cerrado del matrimonio prehispánico se convierte en Ch'anantskua en un lugar abierto: el lugar cerrado que concierne a dos familias (la del novio y la de la novia), que guarda misterios, objetos y ritos sagrados, en el abierto da cabida a todos los ojos del pueblo, hay participación entre actor (joven iniciado) y público (adultos).

En cuanto al ritual de la fertilidad en Ch'anantskua, salta a la vista en primer lugar el mismo matrimonio; sin embargo, vale la pena hacer notar el carácter social que lo caracteriza desde los tiempos prehispánicos, así como la marcada hibridación de que ha sido objeto hasta nuestros días. Ya hemos mencionado anteriormente las fiestas prehispánicas de Sicuindiro, Charapusapi y Enanscuicuaro, entre otras relacionadas con la fertilidad. Tales fiestas se realizaban en la época que va desde la petición de la lluvia hasta las cosechas, aproximadamente de abril a octubre. Las fechas del calendario p'urh'pecha que marcan estas fiestas coinciden con las celebraciones cristianas del 15 de mayo y 24 de junio, día de san Isidro Labrador y de san Juan respectivamente. Ambos santos, aunque tienen las fechas propias de celebración, también van en la procesión de Ch'anantskua. La fiesta religiosa del primero corresponde al mes de Parandatzícuaro, "paranini, llevar algo en la cabeza y tzikua, maíz (...) recién nacido» ${ }^{25}$, por lo que corresponde a la fertilidad. En lo que respecta a la fiesta de san Juan, ésta se ubica en el mes p’urhépecha de Huáscata-Cónscuaro «mes del poder, simbolizado en las flechas, pero también era el mes de la escarda. Uashakani, sentarse, estar en el poder y kúnscani, escardar. Mientras la gente escardaba, los poderosos (...) bebían, celebraban, comían y cantaban a orillas de los ecuaros» ${ }^{26}$.

El calendario p'urhépecha se encuentra organizado en torno al ciclo de la producción del maíz. Este ciclo comienza con la festividad de petición de las lluvias a los dioses de las cuatro partes del mundo; siguen a ésta celebraciones en torno a la preparación de la tierra, la plantación, etapas de crecimiento, y cosecha de este grano; de aquí que podamos decir que se trata de un ritual que va pasando por etapas, y que, en la celebración de éstas, tienen participación prioritaria personas de edades y clases sociales determinadas, de acuerdo al periodo de desarrollo del maíz de que se trate.

En relación a las fechas de la fiesta del toro de petate, podemos observar que coincide también tanto con la celebraciones 
p'urhépecha como con la cristianas, ya que la danza de este toro "se realiza en los días de carnaval (...) o durante el ciclo del nacimiento-muerte de Cristo: Corpus, día de la Candelaria (2 de febrero) San Juan, Domingo de Ramos» ${ }^{27}$. La coincidencia con los antiguos michoacanos se encuentra en las festividades del desarrollo cíclico del maíz, y con las fiestas religiosas de la Iglesia católica, sin duda en la de San Isidro Labrador y la de San Juan.

En cuanto a los toritos, algunas personas de Carapan, como el señor Santos Alejo, pretenden darle a la fiesta un origen propio de la región arguyendo que por eso se borda en la servilleta la imagen del toro; sin embargo, hace más de seis décadas, a decir de la señora María del Refugio Alejo Rodríguez, «las servilletas eran blancas y se llevaban a las bodas, esto entre los años 40 y 42 (...), la imagen del toro bordado comenzó, tal vez, como en los años $50{ }^{28}$, lo que quiere decir que anteriormente servilleta y toro fueron parte de celebraciones distintas y que la unión de ambos se da en el momento en que Ch'anantskua adopta al Torito de petate.

Tal parece que, con la incorporación del Torito de petate a Cb’anantskua, también se agregan las banderillas de colores que portan las muchachas cuando llevan la leña al atrio del templo, puesto que es propio del torito ir «adornado con enormes banderillas de papel de estraza o de china» ${ }^{29}$.

Pero no sólo el torito mencionado se suma a Ch'anantskua, también ésta le imprime un rasgo propio a aquél, puesto que en los pueblos p'urhépecha, en la fiesta del Torito de petate, reparten "gratis muchos tamales (...) comenzando por el señor cura» ${ }^{30}$.

A la fiesta de los toritos que celebran en la ciudad acuden «los rancheros de ambos sexos (...); vienen esos días a pasar el carnaval a la ciudad; y así es de ver a los vecinos de las haciendas o rancherías cercanas ir comiendo públicamente cañas de castilla, naranjas, etc., y seguir a los toritos de petate por todas partes» ${ }^{31}$; esto explica también por qué actualmente, en la celebración de Ch'anantskua, se intercambian chapatas por cañas de azúcar.

Después de exponer las coincidencias de Ch'anantskua con símbolos y elementos de otras culturas, podemos concluir afirmando que tales concurrencias tienen como punto de contacto las fechas de celebración, y que la concordancia cultural que posee nuestra fiesta con las culturas cristiana y africana se basa en que las tres aluden a la fertilidad de la tierra de alguna forma. Sin embargo, no es nada fácil deslindar en Ch'anantskua una cultura de otra, un tiempo de otro tiempo, mucho menos un símbolo de otro símbolo; de aquí que nuestra intención, en este artículo, no sea la de resolver este problema, sino la de mostrar elementos y fechas que contribuyen al abigarramiento cultural de esta fiesta-representación del pueblo de Carapan.

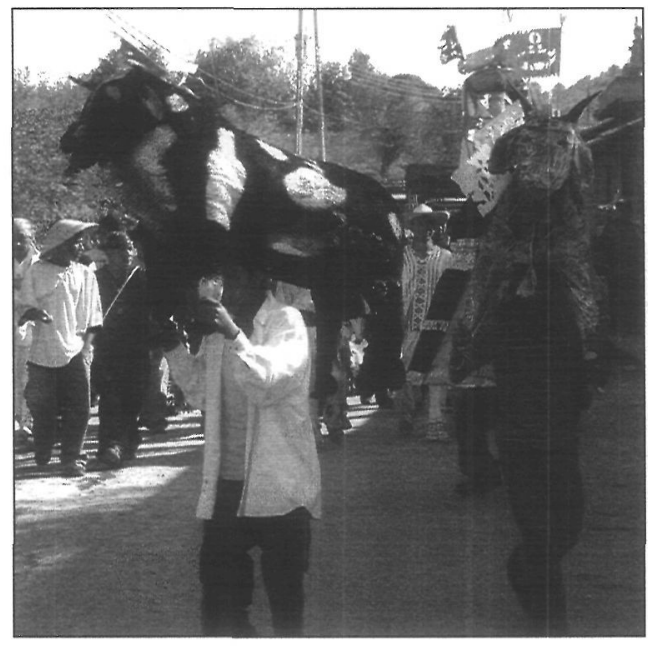

El «torito de petate».

\section{BIBLIOGRAFÍA CITADA}

Alcalá, Jerónimo de, Relación de Michoacán, México, SEP, 1988.

Aguilar Ortiz, José Guadalupe, Carapan: ir escribiendo, Zamora, Editora del Semanario Guía, 1997.

Aguirre Beltrán, Gonzalo, La población negra de México, México, FCE, 1989.

Álvarez de Miranda, Ángel, Ritos y juegos del toro, Taurus, Madrid, 1962.

Amós Martínez, Jorge, Los toros de petate. Una tradición de origen africano traida por los esclavos negros en el siglo XVII, tesis, Facultad de Historia de la UMSNH, 1999.

Ch'anantskua. El juego de la madurez (vídeo), realización y guión de Dante Cerano Bautista, Videoteca Iberoamericana, México, 1999.

Deschamps, Hubert, Las religiones del África negra, EUDEBA, Buenos Aires, 1962.

Eliade, Mircea, Mito y realidad, Barcelona, Labor, 1992.

- Lo sagrado y lo profano, Barcelona, Paidós,1999.

- Tratado de historia de las religiones, México, Era, 2004.

- Historia de las creencias y de las ideas religiosas, Barcelona, Herder, 1999.

López, José Carmelo, El día que murió un imperio, Uruapan, CONACULTA, Gobierno del Estado, Secretaría de Cultura, 2005.

Torres, Mariano de Jesús, «Los toritos de petate», en Juan Hernández Luna y Álvaro Ochoa Serrano, Fiestas y costumbres morelianas del pasado inmediato, UMSNH, El Colegio de Michoacán, 1991.

27

Jorge Amós Martínez Ayala, op. cit., pág. VI.

28

Doña María del Refugio Alejo Rodríguez, vecina de Carapan.

29

Mariano de Jesús Torres, «Los toritos de petate», en Juan Hernández Luna y Álvaro Ochoa Serrano, Fiestas y costumbres morelianas del pasado inmediato, Morelia, UMSNH, El Colegio de Michoacán, 1991, pág. 156.

30

Ibidem, pág. 161.

31

Ibidem, pág. 159. 